\title{
A Cross-Cultural Comparative Study of Gratitude Strategies between Iranian and Malaysian Postgraduate Students
}

\author{
Atieh Farashaiyan ${ }^{1} \&$ Tan Kim Hua ${ }^{1}$ \\ ${ }^{1}$ School of Language Studies and Linguistics, University Kebangsaan Malaysia (UKM), Bangi, Malaysia \\ Correspondence: Atieh Farashaiyan, School of Language Studies and Linguistics, University Kebangsaan \\ Malaysia (UKM), Bangi 43600, Selangor, Malaysia. Tel: 60-17-327-6098. E-mail: \\ atieh_farashaiyan@yahoo.com
}

Received: January 20, 2012

Accepted: February 25, 2012 Published: June 1, 2012

doi:10.5539/ass.v8n7p139

URL: http://dx.doi.org/10.5539/ass.v8n7p139

\begin{abstract}
This study describes and compares the gratitude strategies utilized by Iranian EFL and Malaysian ESL learners in facing different situations. Data were cumulated from 20 Iranian and 20 Malaysian postgraduate university students having the same language proficiency through a Discourse Completion Tasks Questionnaire. Social status, size of imposition and gender are contextual and social variables which were investigated for two groups of learners in this study. Results of the study illustrated certain commonalities and differentials in terms of the strategies and type of gratitude used by Iranian and Malaysian students. A detailed analysis of the use of the gratitude strategies revealed significant differences in communicative ways of Iranian and Malaysian postgraduate students reflecting insights into understanding the differences in cultural values and norms in two non-western cultures. The results also illustrated that the two contextual factors and gender affect significantly on the type and frequency of the strategies.
\end{abstract}

Keywords: cross-cultural pragmatics, gratitude strategies, speech act

\section{Introduction}

Thanking is one of the speech acts or communicative acts frequently and abundantly utilized in human interactions. Each individual gives thanks in an assortment of occasions and situations in his/her daily life interactions with family members, friends, classmates, acquaintances and strangers. Understanding and producing the speech acts that is appropriate to the situations in which one is functioning is of the essence in pragmatics domain generally and the speech act performance particularly, because failure to do so may result in misunderstandings and miscommunications.

Eisenstein and Bodman (1986: 167) have defined gratitude or thanking as a kind of illocutionary act which a speaker performed it based on the act done by the hearer in the past. This performed act has some benefits for the speaker and the speaker believes in this matter. Therefore, the speaker has the feeling of gratefulness or appreciation and expresses his/her feeling through an expression of thanking or gratitude.

The utilization of gratitude might vary cross-culturally. Coulmas (1981: 75) states that the social links between the interlocutors and the innate characteristics of the proposition of gratitude act to specify the extent of gratitude to be uttered in a specific situation. For example, 'thank you' used in British English as a formal marker while in American English it is utilized as thanking ( Hymes, 1972, cited in Eisenstein and Bodman, 1993: 65). As such, studies done on speech acts have revealed that the identical communicative act might be understood completely different cross-culturally (Han, 1992). In addition, Wolfson (1981: 123) declares that speech acts vary across diverse cultures as how they are understood as well as in their frequency, distribution and the functions they have.

However, as Bodman and Eisenstein (1988:1) point out "foreign or second language learners often assume that the expression of gratitude is universal and remain unaware of significant differences in its cross-cultural realization". Even though the universality of speech acts is true, the contents and the frequency of their occurrence are related to specific cultures. As such, learners of the target language do not expect to come across a variety of strategies in the thanking behavior in their interactions with each other cross-culturally. Speech acts can reflect the fundamental social norms and cultural values of the target language. The misunderstanding in the 
production of the appropriate speech act and the perception of the intended meaning is due to the dearth of the cultural, social, and pragmatic context in cross-cultural communication. As such, knowing how to use the speech acts in the target language of second or foreign language learners is important.

Regarding the study of speech acts cross-culturally, most probes have been done on linguistic realizations of speech acts in diverse languages. So, despite the number of empirical studies conducted on speech acts and interlanguage pragmatics in general, and on cross-cultural pragmatics probing the pragmatic differences between two languages in particular, few studies have touched on the variation of the two cultures regarding the performance of pragmatics generally and speech act particularly. Moreover, with the emergence of latest global realities such as the outweigh of non-native speakers of Englishes compared to native-speakers of English and the upsurge of contact between the speakers of "Englishes" in some areas such as education, trade, culture, and the like, it seems necessary to compare and contrast the pragmatic production of so-called non-native speakers of "Englishes."

In addition, Blum-Kulka et al. (1989) contend that speech acts studies necessitate the shift from western cultures towards non-western or eastern cultures in their domain of the study. While the literature abounds with the study of requests and to some extent on apologies, the speech or communicative act of gratitude has not been touched upon so much. Therefore, this study response the afore-mentioned needs. It seeks to (a) compare the frequency and type of the gratitude strategies utilized by Iranian and Malaysian postgraduate students to express thanking or gratitude and (b) to study the difference in expressing gratitude between males and females. Considering the objectives of the study, the following research questions are crystallized:

1-How do gratitude strategies resemble and vary between Iranian EFL and Malaysian ESL learners in terms of frequency and typology in English?

2-How do gratitude strategies resemble and differ between male and female learners in terms of frequency and typology in English?

Among the wealth of researches done on the gratitude speech act cross-culturally, Apte's (1974) probe is one of the earliest investigations of expressions of gratitude. He did a comparison of expressing gratitude in Marathi and Hindi to giving thanks in American English and found that " the usage of gratitude expressions in American culture is much more extensive than in South Asian communities" (p. 84). While in American English expressing the thanks for favors, gifts or services is deemed appropriate and anticipated, for Marathi and Hindi giving thanks to family members or close friends for favors breaches the feeling of closeness since it is the responsibility of family members and close friends to assist each other.

Eisenstein \& Bodman, (1986), Bodman \& Eisenstein (1988) made a comparison of the use of expressions of gratitude by groups of participants having diverse language backgrounds and American English native speakers. They found out that while certain language groups outperformed others, e.g. the Russian speakers outweighed those of the Japanese speakers, the difficulties of non-native speakers were serious and extensive (1986:173).

Following the above probes, Hinkel (1994) did an investigation on cross-cultural comparison of attitudes regarding the thanking speech act. He focused on the differences between non-native speakers and native speakers with extensive exposure to the second language culture. The participants consisted of 199 advanced Chinese, Indonesian, Korean, Japanese, Spanish and Arabic learners. Data were cumulated through a role-play method in which the participants had to reply to a specific interaction with an appropriate statement from several choices provided. Results showed that there were some differences between native language groups and native speakers of English in perceiving the appropriate expressions of gratitude.

In another study, Nakamura (2005) probed on the cultural differences in the strategies of thanking of native speakers of German and Japanese through a Discourse Completion Test as well as a Multiple Discourse Choice Test. The findings illustrated that while the Japanese speakers made use of the thanking and apology expressions in all situations, German speakers mainly utilized thanking expressions in the same situations. Additionally, the study showed that the Japanese native speakers had much sensitivity and attention to the situational variables, whereas the native speakers of German and the Japanese EFL learners were hardly affected by these variables.

Cheng (2005) examined how Chinese and English native speakers of English give thank regarding the length of speech and use of strategies using a Discourse Completion Task Questionnaire. The result suggested that native speakers of Chinese and native speakers of English prefer different strategies to express gratitude in all situations. They performed differently regarding the utilization of strategies and length of speech.

In another study, Ahar and Eslami-Rasekh (2011) sifted through the strategies used by native English and Persian speakers for expressing gratitude. Moreover, a comparison was made between the strategies of Persian 
EFL learners and English strategies to find the differences that may exist between these two languages and cultures. Data were cumulated by means of an open-ended DCT for studying participants' responses and verbal reactions to diverse situations. The findings were suggestive of this matter that Persian EFL learners do transfer their first language pragmatic norms to the target language to some extent due to their perception of the universality of these norms.

Keeping the trace of other studies, Ozdemir \& Rezvani (2011) scrutinized the production of non-native speakers regarding the thanking speech act in an EFL context. The subjects included Turkish and Iranian advanced speakers of English. They were examined in how they expressed gratitude regarding the strategy use and length of speech through a DCT. The results of the study showed that both Turkish and Iranian speakers of English made use of most frequently similar strategies for thanking; however, they utilized the length of speech to some extent differently.

With reference to the studies discussed, the present study aims at investigating and comparing the Iranian and Malaysian students' performance in using the gratitude strategies in terms of frequency and typology and it also compares the differences between genders regarding the application of the strategies.

\section{Materials and Methods}

Two groups of postgraduate students took part in this research: twenty Iranian and twenty Malaysian postgraduate university students majoring in diverse academic fields at Malaysian universities of Putra, Kebangsaan and Malaya. They were selected based on their performance on the TOEFL proficiency test .These participants were equally chosen (20 male and 20 female).

Two instruments utilized in this research included Nelson English language proficiency test and Discourse Completion Test (DCT). Nelson test comprised 50 multiple choice items consisting of grammar, vocabulary, and also reading comprehension. The Discourse Completion Task (DCT) utilized included a short description of the situations followed by a space to be answered by the participant. Theses 10 discourse situations were developed so that to mirror the amalgamation of diverse degrees of power and size of imposition. Regarding the power difference, the addresses can be lower, equal and higher in terms of age and status. Considering the social intimacy or distance of the interlocutors, participants were to interact with people who were familiar with and it can be said that social distance was considered as a controlled variable.

As far as the size of imposition was concerned, the big favor indicated either difficult work necessitating much time and/or physical or financial hardness for the hearer, or the size of the benefit that the speaker received from the hearer of the conversation; e.g. the favor of a friend who offers $500.00 \$$ loan to the speaker was considered as a big favor, while giving back the speaker's pen was of fairly low level of imposition, since a little work involved only temporary actions or an small expense. The Iranian EFL and Malaysian ESL students were required to answer the situations to express their gratitude in their foreign or second language.

The data collected for this study were analyzed according to the taxonomy used by Ahar \& Eslami-Rasekh (2011) in terms of the two major contextual factors, namely, the size of imposition or magnitude of the favor and social status. And in each analysis the two groups of responses, Malaysians and Iranians were examined. A detailed description of the ten scenarios in relation to the combination of the two factors i.e. size of imposition and social status is presented in Table 2 .

Table 1. The distribution of contextual factors

\begin{tabular}{cccc}
\hline Situation & Brief description & \multicolumn{2}{c}{ Contextual factors } \\
\cline { 2 - 4 } & & Size of imposition & Social Status \\
\hline 1 & Fixing the computer & + & $=$ \\
2 & 500 \$ loan & - & $=$ \\
3 & Cleaning your face & - & + \\
4 & Finding your pen & + & + \\
5 & Salary Raise & + & + \\
6 & Recommendation letter & - & + \\
7 & Answering a question & + & - \\
\hline
\end{tabular}


Table 2.

\begin{tabular}{ccc}
\hline Social Status & Big favor & Small favor \\
\hline Lower & Helping with luggage (Situation 5) & Bringing coffee \\
& & (Situation 10) \\
Equal & Fixing the computer & Cleaning your face \\
& (Situation 1) & (Situation 6) \\
& 500 \$ loan & Finding your pen \\
& (Situation 2) & (Situation 7) \\
Higher & Salary Raise & Answering a question \\
& (Situation 3) & (Situation 8) \\
& Recommendation letter & Keeping the door open \\
& (Situation 4) & (situation 9) \\
\hline
\end{tabular}

\section{Results and Discussion}

The DCT utilized in this study entails ten scenarios including four scenarios involve higher social status of the addressee, four involve equal social status of the interlocutors, and two situations involve lower social status of the addressee. In each group of the situations related to a special social status, half involve a high size of imposition and the other half involve a low size of imposition. For instance the four items that embody higher social status include two situations for favors with a significant size of imposition and two situations for a relatively small size of imposition, in order that the effect of this social variable regarding different sizes of favors can be investigated.

\subsection{Higher Social Status}

\subsubsection{Iranians}

Considering the four items involving an interlocutor with a higher social status $(3,4,8$ \& 9), Iranian speakers produced different strategies, with respect to the kind and size of the favor. For the third scenario, the most frequently strategy used was using (Thank you) as a simple expression of gratitude and adding another strategy such as acknowledging the favor as the second most frequently strategy. Promising compensation was utilized as the third strategy. The participants produced some other responses too. For example some of them mixed some strategies with each other or made use of one strategy with the intensifier more than one.

The responses to the professor (situation 4) were nearly like situation 3. Most of the speakers used simple thanking strategies like Thank you and thanks a lot as well as complimenting the person. In this situation, the titles (Prof, Dr, Sir) were used. Examining the other two scenarios ( 8 \& 9) which involved relatively small favors, again the most used strategy was simple thanking in both situations and acknowledging the favor and apologizing as the second and third strategy in situation 8 .

Iranian speakers thanked their professor because of answering their question and keeping the door open for them, by using simple thanking strategy in addition to using the title and intensifier for situation 9 and apologizing or acknowledging the favor for situation 8 .

\subsubsection{Malaysians}

Malaysians expressed their gratitude in these situations with limited variation and a little more strategies compared to their Iranian counterparts (99.98 and 99.97 respectively). They tried to keep their utterances relatively short. Many learners tried to add intensifiers and titles, especially in situations 8 \& 9 to reach the desired level of appropriateness of the higher social status in addition to asking God for rewarding. Besides the strategy of simple thanking, with various wordings, few learners used acknowledging the favor, promising compensation and complimenting the person.

One important similarity in these situations between Iranian and Malaysian students seemed to be the use of titles in addressing the interlocutors mostly in situations 4,8 and 9. For example, they made use of titles like professor, Doctor, Sir, Mr. Boss, president, madam, etc. in their performance. The use of titles is rooted in this matter that the Iranian and Malaysian societies, as two non-western countries are reported to be traditionally non-egalitarian societies as opposed to American as a super-egalitarian society (Beeman, 1988). Therefore, a speaker selects his/her strategy according to the social power, social closeness/distance between the speaker and his/her hearer. In other words, his/her choice of strategy depends on whether he/she is thanking to a higher status( professor or teacher), equal status (classmate), high social distance (stranger) or low social distance (close friend). Observing the hierarchy factor, they made use of similar strategies in a variety of social contexts. 
However, nearly all Iranian and Malaysian students employed one expression of gratitude in these four situations as the dominant strategy. Simple thanking, and more specifically, thank you, was the strategy that these participants considered most appropriate for these scenarios. One interesting point observed was that generally in all of these situations, involving both big and small favors, participants tried to keep their utterances relatively short and brief. This result is in agreement with the findings of Eisenstein and Bodman (1986) and confirms one aspect of Wolfson's Bulge Theory (1989), which is, identifying brevity in communications between socially distant interlocutors.

\subsection{Equal Social Status}

The participants again employed the simple thanking as the most frequently used strategies in all four situations $(1,2,6 \& 7)$. Whenever the participants faced with someone who had the same social status as them, they produced the simple strategies depending on the kind and size of the favor.

\subsubsection{Iranians}

Iranian participants made use of different strategies of gratitude for each situation. All speakers used simple thanking at the beginning of the sentence accompanied by a few other strategies such as acknowledging the favor, complimenting the person and promising compensation as the complementary ones.

In the case of lending the money (situation 2), Iranian participants employed the same strategies. The only significant difference was using the strategy of promising compensation compared to situation 1. Many speakers considered it necessary to mention the kind or exact time of repayment. These statements can be considered supporting acts that are added to the head acts of thanking.

When a friend brought attention to something on the speaker' face (situation 6), Iranian participants mostly used the simple thanking strategy and expressed their embarrassment in some cases and then simply thanked their friends. Iranians employed acknowledging the favor in addition to simple thanking strategy.

For the seventh situation, Iranian speakers used another strategy that was not used in any other situations of the questionnaire. Considering the value and the price of the pen, some speakers referred to the value of their interlocutors and tried to raise their worth by lowering the value of the pen. On the other hand, the speakers directly or indirectly offer their pen and imply that the hearer could keep it for him/herself. Accordingly, this semantic formula can be considered a strategy of ostensible speech act.

\subsubsection{Malaysians}

Malaysian students produced similar strategies in their responses to these situations. Malaysians made use of more strategies in situation two compared to their Iranian counterparts while Iranians produced more strategies in the first situation. Regarding the other two situations ( $6 \& 7)$, the frequency of the strategies were the same between these two groups. After the strategy of simple thanking, acknowledging the favor was the second most frequent strategy for the first situation and promising compensation, complimenting the person and acknowledging the favor were the second, third and forth strategies for the second situation. The data shows that Malaysian students used more than one strategy in situation two and the utterances are mostly long. This shows the understanding of the big favor by the participants.

When responding to situations 1 and 2, nearly most of Iranian participants employed simple thanking for both of these situations. One of the differences in strategy use between these two situations was adding more intensifiers to the responses of the first scenario. In the case of situations 6 and 7 with small favor, simple thanking was the most common strategy used. Complimenting the person was the second most frequently used strategy. Other strategies were not utilized at all. Some participants didn't answer situation 6 and some responses were short. This is due to the small favor of the action done. Regarding the situation 6 , a few participants stated their embarrassment .The only difference between these two situations was using more intensifiers such as very much and so much in situation 7.

\subsection{Lower Social Status}

\subsubsection{Iranians}

The DCT questionnaire used in this study contained two situations in which the speakers wanted to communicate with someone of lower social status. In order to control the effect of age for people of lower social position, in these scenarios speakers were to interact with people who are younger and possess a lower social status. In many cultures such as Iranian culture elder people are treated politely and respectably, no matter what social status they may have. 
Accordingly, there were two situations $(5 \& 10)$ that speakers were faced with younger interlocutors from a lower social status. In the fifth situation reflecting a big favor, the participant was coming back from a trip and his/her neighbor's son helped him/her with luggage and bags and brought them to the speaker's flat. In situation 10 , a student brought the tutor (participant) coffee. This scenario was put in the DCT in order to signify a relatively small and expected favor.

Iranians used simple thanking as the most frequent strategy besides other strategies such as promising compensation, complimenting the person and acknowledging the favor respectively for the fifth situation and acknowledging the favor, complimenting the person and promising compensation respectively for the tenth situation.

\subsubsection{Malaysians}

The responses of Malaysian students in the situation 5 were similar to their responses in situations 10, except the promising compensation which was used more in situation 5 than 10 . In the situation 5 , simple thanking was accompanied by complimenting the person and promising compensation as the second and third frequently used strategies respectively. On the other hand, simple thanking was the dominant strategy in situation 10 followed by complimenting the person as the second strategy and acknowledging the person as the third. The use of intensifiers and qualifiers were quite noticeable in these situations. In some cases, complimenting the person was used first before the simple thanking in situation 10 .

Considering the second research question, both gender (males and females) in Iranian data (99.97\% for males and $99.96 \%$ for females) and Malaysian one (99.98 for males and 99.97 for females) performed similarly in most strategies, except promising compensation that had the most variation between males and females. As the statistics suggests, male participants made use of more strategies compared to female ones, both Iranian and Malaysian participants.

The outcomes of this research showed that the differences exist in terms of the frequency and type of strategies employed for expressing gratitude in English language between Iranian and Malaysian students. This finding is in line with the other studies by Goddard (1977), Scollon and Scollon (1979), Schmidt and Richards (1980) and Blum-Kulka (1982) which they have observed the cross-cultural differences of speech acts in terms of function, distribution and frequency of occurrence.

Table 3. Frequency of gratitude strategies in two groups of participants (Iranians and Malaysians)

\begin{tabular}{|c|c|c|c|c|c|c|}
\hline \multirow[t]{2}{*}{ Gratitude Strategy } & \multicolumn{2}{|c|}{ Situations $(3,4,8,9)$} & \multicolumn{2}{|c|}{ Situations $(1,2,6,7)$} & \multicolumn{2}{|c|}{ Situations $(5,10)$} \\
\hline & Iranians & Malaysians & Iranians & Malaysians & Iranians & Malaysians \\
\hline Simple thanking & $62.26 \%$ & $76.34 \%$ & $79.31 \%$ & $69.56 \%$ & $56.14 \%$ & $52.38 \%$ \\
\hline $\begin{array}{l}\text { Acknowledging the } \\
\text { favor }\end{array}$ & $13.20 \%$ & $10.75 \%$ & $8.04 \%$ & $7.60 \%$ & $12.28 \%$ & $3.17 \%$ \\
\hline $\begin{array}{l}\text { Complimenting the } \\
\text { person/action }\end{array}$ & $11.32 \%$ & $4.30 \%$ & $3.44 \%$ & $7.60 \%$ & $10.52 \%$ & $34.92 \%$ \\
\hline Apologizing & $3.77 \%$ & $2.15 \%$ & 0 & $2.17 \%$ & $3.50 \%$ & 0 \\
\hline $\begin{array}{l}\text { Asking God for } \\
\text { rewarding the } \\
\text { person/ a good wish }\end{array}$ & $1.88 \%$ & $1.07 \%$ & 0 & $2.17 \%$ & 0 & 0 \\
\hline $\begin{array}{l}\text { Promising } \\
\text { compensation }\end{array}$ & $7.54 \%$ & $5.37 \%$ & $9.19 \%$ & $10.86 \%$ & $17.54 \%$ & $9.52 \%$ \\
\hline Total & $99.97 \%$ & $99.98 \%$ & $99.98 \%$ & $99.96 \%$ & $99.98 \%$ & $99.99 \%$ \\
\hline
\end{tabular}

Table 4. Frequency of gratitude strategy between Iranian male-female responses

\begin{tabular}{lccc}
\hline Gratitude Strategy & Males & Females & Total \\
\hline Simple thanking & $65.11 \%$ & $68.03 \%$ & $66.53 \%$ \\
Acknowledging the favor & $11.62 \%$ & $10.65 \%$ & $11.15 \%$ \\
Complimenting the person/action & $6.97 \%$ & $10.65 \%$ & $8.76 \%$ \\
Apologizing & $3.10 \%$ & $1.63 \%$ & $2.39 \%$ \\
Asking God for rewarding the person/ a good wish & $0.77 \%$ & $0.81 \%$ & $0.79 \%$ \\
Promising compensation & $12.40 \%$ & $8.19 \%$ & $10.35 \%$ \\
Total & $99.97 \%$ & $99.96 \%$ & $99.97 \%$ \\
\hline
\end{tabular}


Table 5. Frequency of gratitude strategy between Malaysian male-female responses

\begin{tabular}{lccc}
\hline Gratitude Strategy & Males & Females & Total \\
\hline Simple thanking & $71.29 \%$ & $70 \%$ & $70.58 \%$ \\
Acknowledging the favor & $8.33 \%$ & $7.69 \%$ & $7.98 \%$ \\
Complimenting the person/action & $11.11 \%$ & $8.46 \%$ & $9.66 \%$ \\
Apologizing & $0.92 \%$ & $2.30 \%$ & $1.68 \%$ \\
Asking God for rewarding the person/ a good wish & $1.85 \%$ & $0.76 \%$ & $1.26 \%$ \\
Promising compensation & $6.48 \%$ & $10.76 \%$ & $8.82 \%$ \\
Total & $99.98 \%$ & $99.97 \%$ & $99.98 \%$ \\
\hline
\end{tabular}

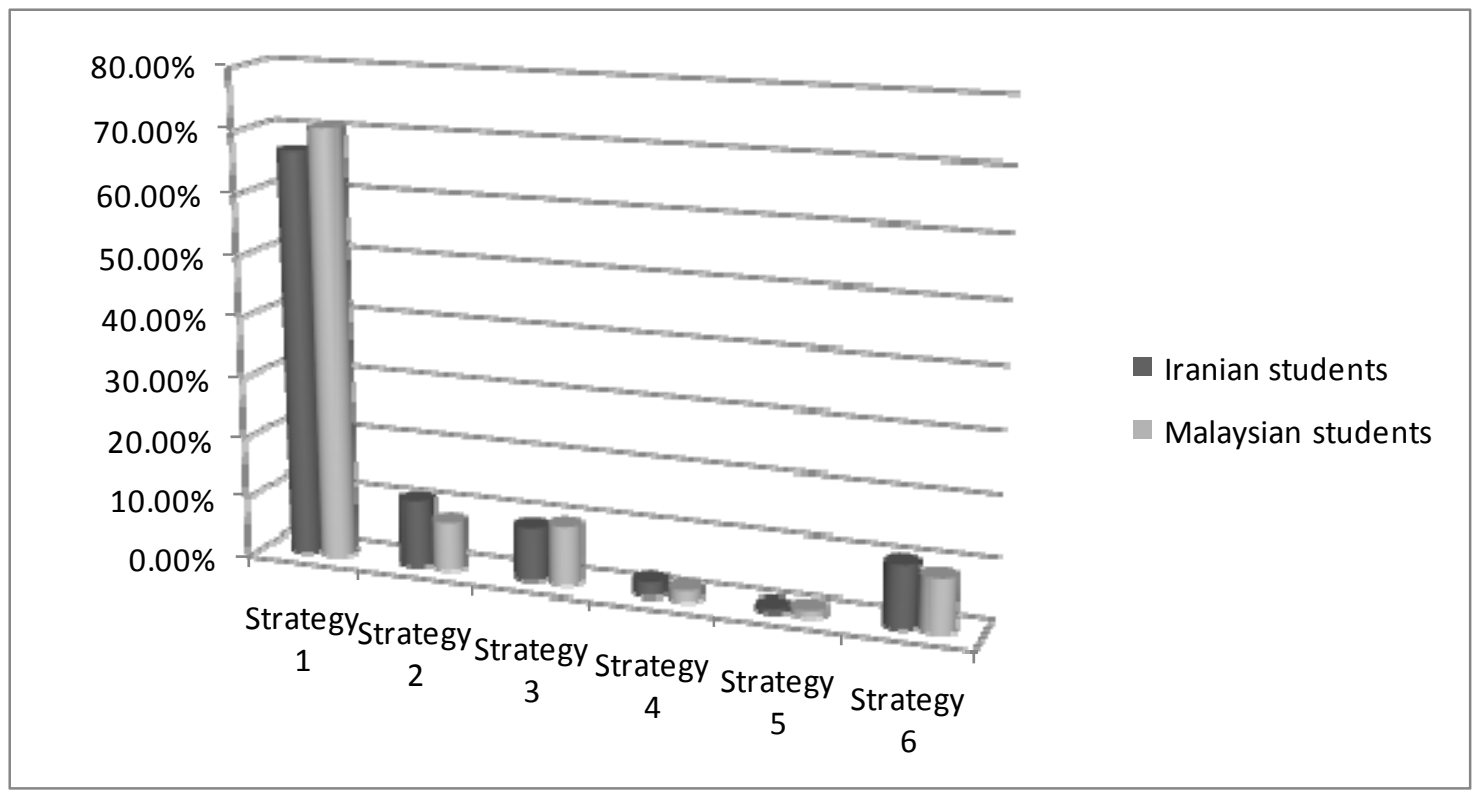

Figure 1. Frequency of gratitude strategies for Iranian and Malaysian students

Note: Strategy 1= Simple thanking, 2- Acknowledging the favor, 3-Complimenting the person/action, 4Apologizing, 5- Asking God for rewarding the person, 6- Promising compensation

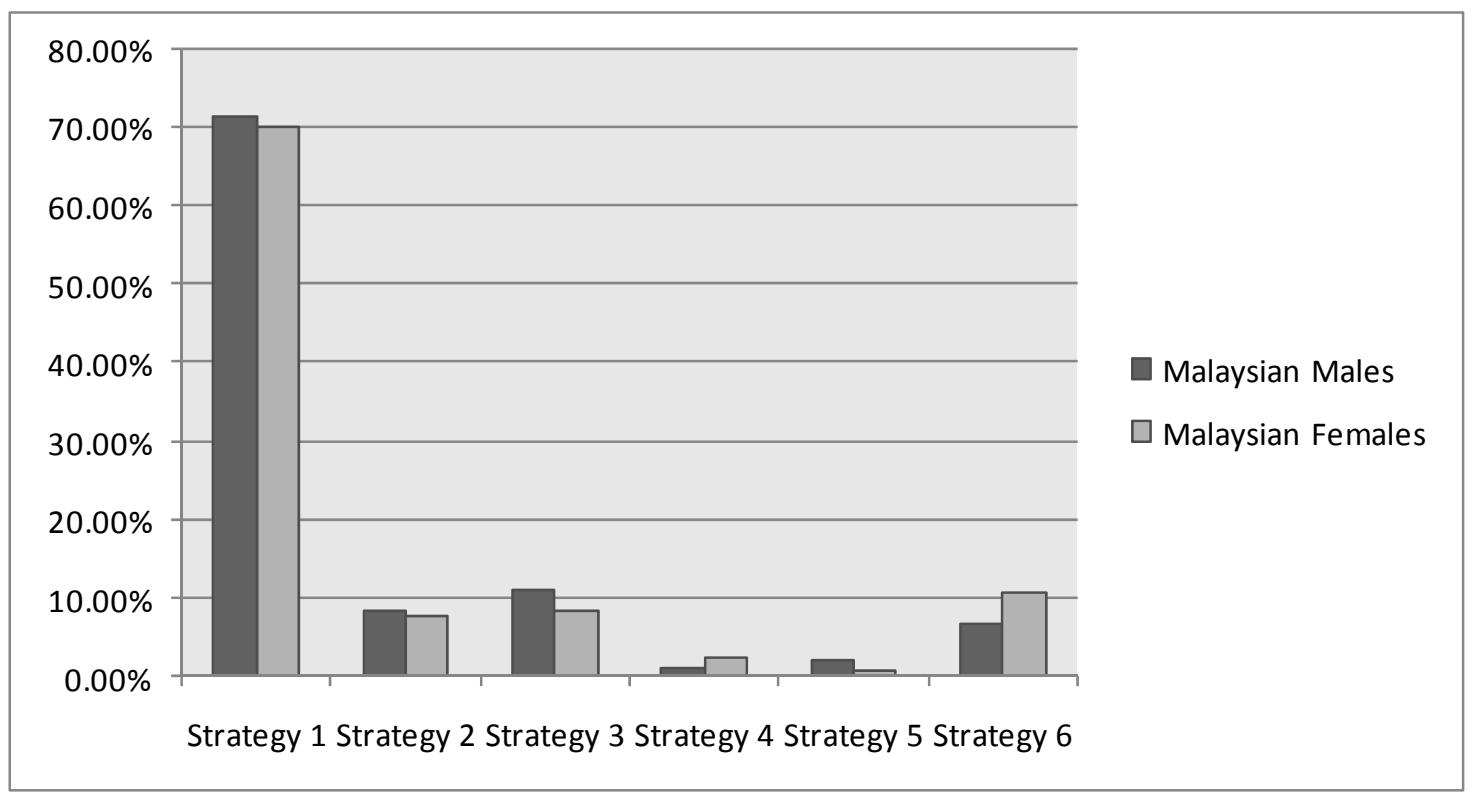

Figure 2. Frequency of gratitude strategies for Malaysian male and female students 


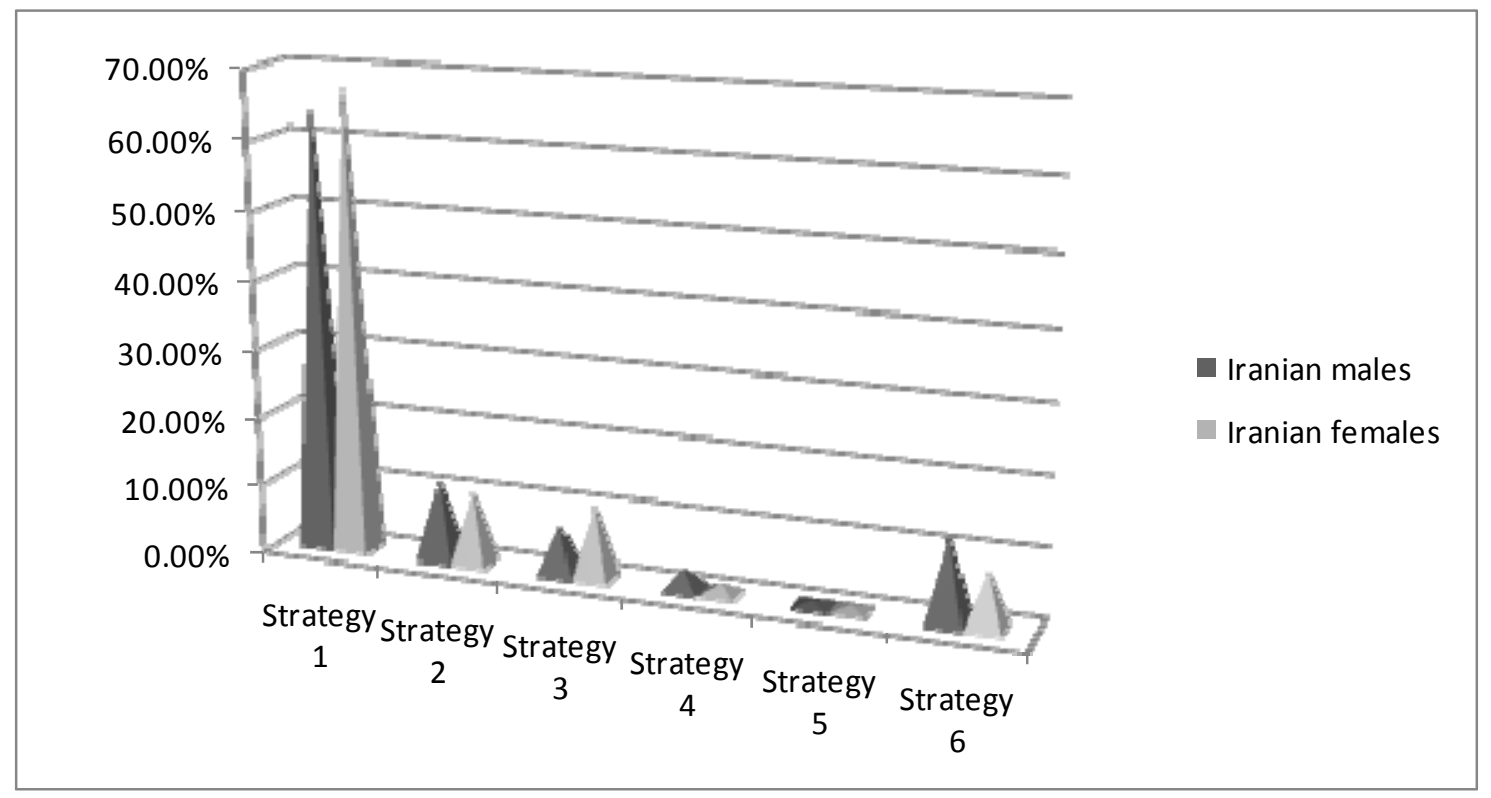

Figure 3. Frequency of gratitude strategies for Iranian male and female students

\section{Conclusion}

The present study described and compared the gratitude strategies of Iranian EFL learners with their Malaysian ESL counterparts. The findings of the present study, though small in scale, propose that the pragmatic performance of the students is pertinent to certain factors other than language proficiency because the participants had more or less the identical level of language proficiency, but in certain situations they dealt with the same thanking situations to some extent differently. For example, Malaysian participants employed more gratitude strategies in comparison with their Iranian counterparts. Such differences might be rooted in a number of factors including the transfer of pragmatic norms and rules from the first language, the EFL/ESL status of the learners, and the like. It is vastly understood that the context plays a noticeable role in deciding the realization strategies of speech acts. For example, the subjects may react in different ways or choose diverse strategies in responding to the situations with the identical speech acts (Bergman \& Kasper, 1993; Cohen, 2004; Maeshiba et al., 1996; Nickels, 2006).

As indicated in table 3, both groups made use of simple thanking as the most frequent one. Iranian students responded in a polite way but their responses were not appropriate based on the social norms of American society. For example, their expressions for thanking their boss and thanking their neighbor's son were quit similar both in terms of strategy and in the number of the frequency of the expressions used. Generally it seemed that they were not equipped with appropriate tools to express gratitude according to the status of the interlocutor here, whereas Malaysian participants considered the situational variables more than their counterparts. In addition, considering the gender issue, male participants made use of more strategies compared to female ones, both Iranian and Malaysian participants. This issue arises the matter of sexism in language use.

Regarding the type of strategies, this study points to this matter that developing learners' linguistic competence for handling intercultural communication is not sufficient. It is of paramount importance and necessity to develop learners' sociocultural and pragmatic competences in order that they can nurture the rules of interaction and politeness of the target language to better develop the intercultural communicative competence as a new direction towards learning the target language and being as a successful non-native speaker as a consequences of globalization as well as English as a lingua franca. Personality factor can also play a vital role in determining the type of the strategy chosen. So, providing learners with the knowledge of the linguistic forms, functional meanings and contextual factors for conveying the intended meanings in an assortment of diverse contexts or situations is vital, particularly when it comes to communication taking place in intercultural context because the differences in realization of speech acts strategies between the two cultures will affect communication and consequently may give rise to misunderstandings. 


\section{References}

Ahar, M., \& Eslami-Rasekh, A. (2011). The Effect of Social Status and Size of Imposition on the Gratitude Strategies of Persian and English Speakers. Journal of Language Teaching and Research, 2(1), 120-128. http://dx.doi.org/10.4304/jltr.2.1.120-128

Al-Falasi, H. (2007). Just say 'thank you': A study of compliment responses. The linguistic journal, 2(1). Retrieved April 17, 2008, from www.Linguistics-journal.com

Apte, M. L. (1974). 'Thank you' and South Asian Languages: A comparative sociolinguistic study. Linguistics, 136, 67-89. http://dx.doi.org/10.1515/ling.1974.12.136.67

Austin, J. L. (1962). How to do things with words. Oxford: Oxford University Press.

Bergman, M., \& Kasper, G. (1993). Perception and performance in native and nonnative apology. In Kasper, G. and Blum-Kulka, S. (Eds.), Interlanguage Pragmatics (pp.82-107). New York, NY: Oxford University Press.

Blum-Kulka, S. (1982). Learning how to say what you mean in a second language: A study of the speech act performance of learners of Hebrew as a second language. Applied Linguistics, 3, 29-59. http://dx.doi.org/10.1093/applin/III.1.29

Blum-Kulka, S., \& Olshtain, E. (1984). Requests and apologies: A cross-cultural study of speech act realization patterns (CCSARP). Applied linguistics, 5, 196-213. http://dx.doi.org/10.1093/applin/5.3.196

Blum-Kulka, S., House, J., \& Kasper, G. (1989). Cross-cultural Pragmatics: Requests and Apologies. Norwood, New Jersey: Ablex.

Bodman, J., \& Eisenstein, M. (1988). May God increase your bounty: The expressions of gratitude in English by native and non-native speakers. Cross currents, 15(1), 1-21.

Cheng, S. W. (2005). An exploratory cross-sectional study of interlanguage pragmatic development of expressions of gratitude by Chinese learners of English. Unpublished PhD dissertations. The University of Iowa.

Cohen, A. (1996). Speech Acts. In S.L. McKay, \& N.H. Hornberger (Eds.), sociolinguistics and language teaching (pp. 383-420). Cambridge: Cambridge University Press.

Cohen, Andrew D. (2004). Assessing speech acts in a second language. In D. Boxer \& A. D. Cohen (Eds.), Studying speaking to inform second language learning (pp. 302-327). Clevedon, England: Multilingual Matters.

Coulmas, F. (1981). 'Poison to your soul': Thanks and apologies contrastively viewed. In F, Coulmas, Conversational routine (pp. 69-91). The Hague: Mouton.

Eisenstein, M., \& Bodman, J. (1986). 'I very appreciate': Expressions of gratitude by native and non-native speakers of American English. Applied linguistics, 7(2), 167-185. http://dx.doi.org/10.1093/applin/7.2.167

Eisenstein, M., \& Bodman, J. W. (1993). Expressing gratitude in American English. In G. K. S. Blum-Kulka (Ed.), Interlanguage pragmatics (pp. 64-81). New York: Oxford University Press.

Eslami-Rasekh, Z., Eslami-Rasekh, A., \& Fattahi, A. (2004). The effect of explicit metapragmatic instruction on the speech act awareness of advanced EFL students. TESL-EJ, 8(2).

Faerch, C., \& Kasper, G. (1987). Perspectives on language transfer. Applied linguistics, 8(2), 116-136. http://dx.doi.org/10.1093/applin/8.2.111

Goddard, D. (1977). Same settings, different norms: Phone call beginnings in France and the United States. Language in Society, 6, 209-219. http://dx.doi.org/10.1017/S0047404500007259

Hinkel, E. (1994). Pragmatics of interaction: Expressing thanks in a second language. Applied Language Learning, 5(1), 73-91.

Hymes, D. H. (1972). On communicative competence. In B. Pride \& J. Holmes (Eds.), Sociolinguistics (pp. 269-293). Harmondsworth: Penguin.

Kasper, G., \& Blum-Kulka, S. (Eds.). (1993). Interlanguage Pragmatics. Oxford: Oxford University Press.

Maeshiba, N., yoshinaga, N., Kasper, G., \& Ross, S. (1996). Transfer and proficiency in interlanguage apologizing. In Gass,S. \& Neu, J. (Eds.), Speech acts across cultures: Challenge to communication in a second language. (pp.155-187). Berlin: Mouton. 
Nakamura, K. (2005). Appreciation Strategies of German and Japanese Native Speakers and German Learners of Japanese. Proceedings of the 4th Annual JALT Pan-SIG Conference. May 14-15. Tokyo, Japan: Tokyo Keizai University.

Nickels, E. L. (2006). Interlanguage pragmatics and the effects of setting. In K. Bardovi-Harlig, J. C. Félix-Brasdefer, \& A. Omar (Eds.), Pragmatics and Language Learning (Vol. 11, pp. 253-280). Honolulu, HI: Second Language Teaching and Curriculum Center, University of Hawai'i at Manoa.

Olshtain, E., \& Blum-Kulka, S. (1985). Cross-cultural pragmatics and the testing of communicative competence. Language Testing, 2(1), 16-30. http://dx.doi.org/10.1177/026553228500200103

Olshtain, E., \& Cohen, A. D. (1989). Speech act behaviour across languages. In H. Dechert \& M. Raupach (Eds.), Transfer in language production (pp. 53-67). Norwood, NJ: Ablex.

Olshtain, Elite. (1989). Apologies across languages. In Shoshana Blum-Kulka, 299 Juliane House, \& Gabriele Kasper (Eds.), Cross-cultural pragmatics: Requests and apologies (pp. 155-173). Norwood, NJ: Ablex.

Ozdemi, \& Rezvani. (2011). Interlanguage pragmatics in action: Use of expressions of gratitude. Procedia Social and Behavioral Sciences, 3, 194-202. http://dx.doi.org/10.1016/j.sbspro.2010.07.032

Schmidt, R., \& Richards, J. C. (1980). Speech acts and second language learning. Applied Linguistics, 1(2), 129-157. http://dx.doi.org/10.1093/applin/I.2.129

Scollon, R., \& Scollon, S. (1979). Intercultural communication. Oxford: Blackwell.

Searle, J. R. (1969). Speech Acts: An Essay in the Philosophy of Language. Cambridge: Cambridge University Press.

Searle, J. R. (1976). A Classification of Illocutionary Acts. Language in Society, 5, 1-24. http://dx.doi.org/10.1017/S0047404500006837

$\mathrm{Yu}$, M. C. (1999). Universalistic and culture-specific perspectives on variation in the acquisition of pragmatic competence in a second language. Pragmatics, 9(2), 281-312. 